Jurnal Ilmu Budaya, Vol. 17, No. 1 Agustus Tahun 2020

\title{
KAJIAN STRUKTUR KEPRIBADIAN FREUD DALAM KISAH 1001 MALAM: STUDI PSIKOANALISIS
}

\author{
Essy Syam ${ }^{1}$, Mita Rosaliza ${ }^{2}$ \\ ${ }^{1}$ Universitas Lancang Kuning \\ 2Universitas Riau \\ Email:essy_fib@yahoo.com,mita.rosaliza@gmail.com
}

\begin{abstract}
This writing deals with analyzing Sigmund Freud's personality structure on Arabian nights (Seribu Satu Malam). The analysis shows that in his actions, the main character, King Shahryar, is controlled by the three components of Freud's personality structures; Id. Ego and Superego. Id controls the king when he is pushed by his Id to marry a woman and kills that woman the following day. He does that everyday for three years. It is pushed by soul drive to get pleasure when his anger and revenge are fulfilled. So, marrying and killing those women are pushed by Id. Ego's domination is seen when the king is eager to listen to his wife's stories and his awareness of his power also the reality he responds in leading him to his actions. At last, Superego brings him back to his good nature when he can finally accept his wife, Shahrazad. Besides, listening to Shahrazad's stories also triggers Superego portrayed by his giving chance for Shahrazad to tell the stories, respecting her and furthermore, the good characters'quality in Shahrazad's stories also contribute to strengthen Superego's domination.
\end{abstract}

Keywords: Freud, personality structure, Kisah 1001 Malam (Arabian Nights)s

\section{Pendahuluan}

Seribu Satu Malam (SSM) adalah sastra epik dari Timur Tengah yang terkenal. Kisah ini lahir pada abad pertengahan. SSM merupakan kumpulan cerita berbingkai yang diceritakan oleh seorang ratu bernama Syahrazad yang menceritakan rangkaian kisah-kisah yang menarik kepada suaminya. Kisah itu diceritakan selama seribu satu malam dengan kisah-kisah dan tokoh yang berbeda-beda.

Raja memiliki kebiasaan yang kejam. Ia akan membunuh setiap wanita yang dinikahinya. Hal tersebut membuat Syahrazad berpikir untuk menemukan 
Jurnal Ilmu Budaya, Vol. 17, No. 1 Agustus Tahun 2020

cara agar kekejaman serupa tidak terjadi

juga pada dirinya. Cara yang ia lakukan ialah berkisah kepada raja setiap malam.

Kisah-kisah yang ia ceritakan membuat raja penasaran dan ingin mendengarkan kisah berikutnya pada malam-malam yang akan datang. Apa yang dilakukan Syahrazad memperlihatkan bentuk interaksi seseorang dalam merespon situasi atau keadaan tertentu.

Dalam menyikapi atau merespon suatu keadaan setiap orang mengambil sikap yang berbeda. Sikap yang diambil bisa menunjukkan tujuan dan prinsip hidup orang tersebut. Prioritas seseorang dalam hidupnya juga dapat dilihat dari keputusan yang diambilnya ketika mesti berhadap-hadapan dengan keadaan tertentu.

Dalam bersikap seseorang bisa jadi dituntun oleh tuntutan jiwanya yang selalu mengedepankan keinginan untuk mendapatkan kesenangan dan memuaskan hawa nafsunya. Manusia seperti ini biasanya mengejar kesenangan hidup belaka sehingga bersenang-senang tersebut malah menjadi kebutuhannya.
Seseorang dengan prilaku seperti ini, dalam struktur kepribadian Sigmund Freud didominasi oleh $I d$.

Selain itu, ada pula seseorang yang bersikap penuh perhitungan logis. Orang seperti ini biasanya menjadikan logika sebagai dasar dari segala tindakan dan semua keputusan yang diambilnya. Orang yang mendasari segala urusannya pada logikanya ini merupakan struktur kepribadian yang dinamakan Freud dengan Ego. Seseorang yang didominasi oleh Egonya ini memandang segala hal penuh dengan perhitungan sehingga ia memperhitungkan dan mengkalkulasikan segala hal secara logis. Orang seperti ini memandang semua hal dalam hidupnya dengan perhitungan matematis.

Ada pula orang yang bersikap penuh dengan pertimbangan moral yang selalu mejadikan moralitas sebagai dasar dan acuan dalam segala prilakunya, yang dalam struktur kepribadian Freud dinamakan Superego. Seseorang yang didominasi oleh Superego menjadi sosok yang sangat memperhatikan moralitas, yang penuh pertimbangan terhadap 
Jurnal Ilmu Budaya, Vol. 17, No. 1 Agustus Tahun 2020

konsep benar dan salah, baik dan buruk sehingga Superego ini menuntun seseorang tersebut menjadi sosok yang memiliki moralitas yang baik.

Berdasarkan paparan yang telah dijelaskan di atas maka kajian ini menganalisis Kisah Seribu Satu Malam dengan menggunakan teori struktur kepribadian Freud.

\section{Konsep}

Sigmund Freud adalah seorang psikoanalis yang kontroversial. Teori psikoanalis yang ia perkenalkan tidak bisa diterima semua orang. Di Jerman ia ditolak tetapi berterima di Prancis. Banyak yang tidak bisa menerima gagasan yang diusung Freud yang cenderung selalu mengaitkan masalah kejiwaan dengan masalah seksual dan trauma masa kecil.

Bagi Freud, manusia itu adalah pemimpi dan sebagai pemimpi, manusia tidak bertanggung jawab terhadap tindakannya karena manusia tidak dapat mengubah dirinya. Gagasannya tentang mimpi ini juga mendapat kritikan bahkan menjadi salah satu hal yang memisahkannya dengan Carl Jung muridnya.

Terkait dengan mimpi ini, Freud membaginya menjadi dua bagian : mimpi manifest dan mimpi latent. Bagi Freud, kedua mimpi ini merupakan ekspresi dari unconscious (tidak sadar). Mimpi manifest dapat diingat disaat seseorang terjaga sedanglan mimpi latent tidak dapat diingat sebelum seseorang itu dihipnosis. Freud meyakini bahwa ketika seseorang sedang tidur, pikirannya menciptakan mimpi sebagai jalan untuk memenuhi harapannya. Pikiran tersebut disensor yang menyebabkan timbulnya distorsi dalam tampilan harapan seseorang tersebut dalam mimpinya. Konten mimpi tersebut disensor oleh simbol-simbol yang merupakan bagian yang sangat terkait dengan masa kecil (Sim, 1995: 142).

Lebih dalam lagi, Freud membagi pemikiran manusia dalam tiga bagian yaitu sadar (conscious), bawah sadar (preconscious) dan tidak sadar (unconscious). Kondisi sadar adalah 
Jurnal Ilmu Budaya, Vol. 17, No. 1 Agustus Tahun 2020

bagian pemikiran tempat dimana proses berpikir secara sadar, yang merupakan sumber gagasan dan sumber pemahaman, pemikiran logis, realitas dan prilaku yang beradab. Sedangkan bawah sadar (preconscious) merupakan tempat informasi yang mudah diakses disaat diperlukan. Yang terakhir tidak sadar (unconscious) merupakan bagian pikiran yang merepresi dan menempatkan hal-hal yang dianggap tidak memerlukan perhatian karena kualitas informasi yang dianggap tidak penting. Bagian ini tidak dapat diakses kecuali dengan hipnosis.

Dalam pembahasan selanjutnya Freud mengkaitkan pemikiran, manusia tersebut dengan struktur kepribadian (Id, Ego dan Superego). Bagian-bagian ini memiliki kaitan yang sangat erat sehingga tidak dapat dipisahkan satu sama lain. Jadi, bila berbicara tentang struktur kepribadian, maka mau tidak mau pembahasan tentang pemikiran manusia juga diuraikan untuk memperlihatkan kaitan erat antara keduanya.

Freud suggested a three-part, rather than a two-part, model of the psyche, devIding it into the Ego, the
Superego and the Id. These three 'levels' of the personality roughly corresponding to, respectively, the consciousness, the conscience, and the unconscious. (Barry, 2002: 97)

Jadi, Freud membagi struktur kepribadian pada tiga sistem yaitu: $I d$, Ego dan Superego. Id merupakan struktur yang sebagiannya terletak pada sadar dan sebagian lagi pada tidak sadar. Id merupakan sumber semua energi psikis karena itulah Id merupakan bagian yang penting dalam kepribadian. Bagian ini merupakan pulsi yang mendorong untuk memenuhi kebutuhan biologis, yang merupakan kebutuhan primitif yang didorong oleh keinginan untuk mendapatkan kesenangan (pleasure) karena itulah Id bekerja berdasarkan prinsip kesenangan yang mendorong manusia untuk mendapatkan dan memenuhi semua keinginan dan kebutuhan. Pada saat keinginan dan kebutuhan tidak terpenuhi, maka kondisi ini dapat menimbulkan kecemasan dan ketegangan. Jadi, Id ini bekerja untuk mengurai ketegangan yang ditimbulkan oleh prinsip kesenangan tadi dengan cara 
Jurnal Ilmu Budaya, Vol. 17, No. 1 Agustus Tahun 2020

memenuhi keinginan dan kebutuhan yang

diinginkan atau yang dibutuhkan saat itu.

Sebagai contoh bila seseorang merasa lapar, maka Id mendorongnya untuk mendapatkan makanan yang akan memenuhi kebutuhannya saat itu sebagai jalan mengatasi kecemasan dan ketegangan yang diakibatkan oleh rasa lapar tersebut. Maka, dengan mengatasi rasa lapar, maka makan dapat memenuhi keinginan sampai Id terpuaskan. (Hima, 2015 dalam https://www.kompasiana.com/ghusyarahi mapramudhitan/552fa1546ea834a8048b4 586/Id-Ego-Superego-psikoanalisis-

kepribadian-sigmund-freud).

Selanjutnya Ego merupakan bagian yang berkaitan dengan realitas yang mengontrol pulsi dan keinginan dan larangan superego dengan lebih mengedepankan logika. Ego menjembatani kedua struktur lainnya $I d$ dan Superego, "Freud defined the Ego in relation to two other terms: the Id or the reservoir of affective energy and the Superego, the Ego- Ideal or the representative of external reality.
(Lechte, 1995: 23) Ego berperan penting dalam memastikan dorongan Id yang dapat diekspresikan dengan cara yang dapat diterima dalam dunia nyata. Jadi, Ego mengekspresikan dorongandorongan yang ingin dipuaskan oleh $I d$ dengan cara yang sesuai dengan realitas. Contohnya, seseorang yang ingin makan coklat, bila seseorang tersebut didominasi oleh $I d$, maka dia akan memakan coklat sebanyak yang diinginkannya, namun bila Egonya lebih mendominasinya, maka dia hanya akan memakan sekeping coklat saja.

Ego bekerja pada proses berpikir yang rasional dan realistis yang membawa pada problem solving. Jika suatu rencana tidak berjalan lancar, Ego akan mengajak sesorang untuk berpikir dan mencari solusi lainnya. Tindakan ini dinamakan reality testing yang membawa seseorang mampu mengontrol impulsimpuls yang memperlihatkan kontrol diri dengan menguasai Ego.

Yang ketiga, bagian yang terakhir adalah Superego. Superego merupakan sensor moral terhadap Ego yang 
Jurnal Ilmu Budaya, Vol. 17, No. 1 Agustus Tahun 2020

\begin{abstract}
merupakan kontrol diri, biasanya mewakili ideologi keluarga (pendidikan keluarga). Superego berkembang pada usia tiga sampai lima tahun pada fase falik dalam perkembangan psikoseksual. Pada fase ini seorang manusia mengenal konsep moralitas dari lingkungannya. Dengan demikian Superego merupakan suatu kesadaran akan nilai-nilai dan moral masyarakat yang disosialisasikan dan diinternalisasi dalam masyarakat lewat berbagai sarana seperti adat istiadat, agama, pendidikan baik formal maupun informal dan sarana-sarana pendidikan lainnya.
\end{abstract}

Dari penjabaran sebelumnya, sudah tergambar bahwa Id dikendalikan oleh prinsip kesenangan dan Ego dikendalikan oleh prinsip kenyataan, dan Superego merupakan bagian yang dikendalikan oleh pinsip moralitas dan idealitas.

Jadi, Superego dapat menjadi pedoman dalam menilai baik dan buruk (benar-salah). Misalnya, seseorang terjebak macet saat pulang kerja. Ia hanya ingin motornya bergerak. Namun bila ia memaksakan motornya maju, ia akan menyenggol motor yang berada di depannya dan dapat mematahkan spion kendaraan di depannya. Maka bila dia memutuskan untuk tidak memaksakan menyalip kendaraan di depannya, disaat itu Superego menuntunnya mengambil keputusan itu.

Superego terkait dengan aturan yang standar dan tingkah laku yang baik, dimana tingkah laku ini mendapat persetujuan dari orang-orang yang memiliki otoritas seperti orang tua dan sosok lainnya. Dengan mematuhi aturan standar tadi akan menimbulkan rasa senang, bangga dan sejenisnya. Selain itu, Superego juga terkait hati nurani yang berhubungan dengan hal-hal yang dianggap buruk atau baik oleh masyarakat. Bila suatu prilaku dilarang, ini menunjukkan bahwa prilaku tersebut dapat menyebabkan hal-hal yang buruk. Dengan demikian, Superego menekan prilaku yang tidak dapat diterima dengan cara menekan keinginan dan dorongan Id dan mendorong tindakan yang idealis dan realisitis. Jadi Superego berperan sebagai acuan moralitas dan nilai-nilai yang 
Jurnal Ilmu Budaya, Vol. 17, No. 1 Agustus Tahun 2020

digunakan oleh Ego untuk bertindak dan mengambil keputusan. (BEM UnDip, 2015)

Ketiga bagian atau ketiga
komponen kepribadian ini saling
mempengaruhi dan saling berinteraksi.
Ego dan Superego berperan dalam mengatur dan mengarahkan pemenuhan Id dengan menuntun pada tatanan atau aturan yang didasari pada nilai moral. Karena itulah ketiga komponen ini harus berada pada kondisi yang seimbang. Bila ketiganya berada dalam keseimbangan, maka akan menciptakan pribadi yang sehat. (Hima, 2015 dalam https://www.kompasiana.com/ghusyarahi mapramudhitan/552fa1546ea834a8048b4 586/Id-Ego-Superego-psikoanalisis-

kepribadian-sigmund-freud.

Sebagai contoh yang lebih utuh yang menggabungkan ketiga konponen ini dapat kita cermati misalnya seorang gadis remaja yang berjanji dengan temannya untuk pergi ke Mall, namun ia belum mengerjakan tugas sekolahnya yang harus dikumpulkan besok. Id akan memujuknya untuk pergi ke Mall dan mengerjakan tugasnya sepulang dari Mall, sedangkan Superego mengajaknya untuk mengerjakan tugasnya terlebih dahulu. Dan Ego adalah pengambil keputusan yang memutuskan apakah mengikuti ajakan Id atau Superego setelah mempertimbangkan sisi baik dan buruknya.

\section{Seribu Satu Malam}

Kisah ini menceritakan tentang dua kerajaan yaitu Kerajaan Sasan dan Smarrkand al - Ajam, yang dipimpin oleh dua bersaudara. Kerajaan Sasan diperintah oleh Raja Shahryar, sedangkan Kerajaan Samarkand al-Ajam diperintah oleh Raja Shahzaman. Kedua Raja tersebut sangat dicintai oleh rakyatnya karena mereka adalah raja yang bijaksana dan murah hati, serta keduanya memiliki istri yang sangat cantik.

Suatu hari Raja Shahryar pergi menemui saudaranya di Kerajaan Samarkand al-Ajam. Saat di tengah perjalanan ia teringat bahwa hadiah yang akan ia berikan untuk saudaranya tertinggal di atas tempat tidur di dalam 
Jurnal Ilmu Budaya, Vol. 17, No. 1 Agustus Tahun 2020

kamarnya. Maka ia kembali ke istananya

untuk mengambil hadiah tersebut. Namun

saat memasuki kamar alangkah terkejutnya ia, karena mendapati istrinya sedang berselingkuh dengan seorang budak.

Merasa dikhianati, kemarahan menguasainya, dan dia membunuh istrinya dan sejak saat itu dia berubah menjadi raja yang penuh dendam. Lalu untuk melampiaskan dendamnya, sang raja setiap hari menikahi wanita di pagi hari dan membunuhnya keesokan harinya. Hal ini berlangsung selama 3 tahun sehingga akhirnya ia memikahi putri penasehatnya, bernama Shahrazad. Sang ratu yang cerdas dan suka membaca memiliki banyak koleksi cerita dan sang raja tertarik mendengarkan ceritanya sehingga menunda untuk membunuhnya. Pada malam hari Shahrazad mulai bercerita sehingga tak terasa waktu sudah berubah menjadi pagi hari, namun karena Sang Raja ingin sekali mendengar kelanjutan cerita tersebut, maka pagi itu ia menangguhkan kembali hukuman mati untuk istrinya dan menyuruh algojo untuk kembali keesokan harinya. Sang ratu selalu menghentikan ceritanya sebelum cerita tersebut selesai sehingga sang raja penasaran dan menunggu kelanjutan cerita keesokan harinya. Hal ini berlangsung setiap malam sehingga malam ke seribu setelah Shahrazad menikahi Raja Shahryar, Shahrazad tak punya cerita lagi yang bisa diceritakan kepada Raja maka ia pun menceritakan kisah tentang hidupnya sendiri saat itu. Kisahnya membuat raja tersadar dan sejak saat itu sang raja mencintainya.

Sang raja, lalu meminta penasehatnya memanggil 100 ahli tulis untuk menuliskan semua kisah yang telah diceritakan Shahrazad selama seribu satu malam pernikahannya dengan Shahrazad. Kemudian kumpulan kisah tersebut diberi judul Seribu Satu Kisah.

\section{Pembahasan}

\section{A. Id}

Dalam Kisah Seribu Satu Malam dapat kita temukan prilaku tokoh yang didominasi oleh $I d$. Tokoh yang sangat besar didominasi oleh Id adalah Raja 
Shahryar. Keputusan impulsifnya yang membunuh istrinya memperlihatkan hal itu.

Maka ia kembali ke istananya untuk mengambil hadiah tersebut. Namun saat memasuki kamar alangkah terkejutnya ia, karena mendapati istrinya sudah tidak memakai cadar lagi dan disampingnya duduk seorang pembantunya sambil memegang cadar tersebut dan tangan yang lainnya memegang tangan sang istri. Kemarahan dan sakit hati menguasainya sehingga ia membunuh keduanya dengan pedangnya. (SSM: 1)

Kemarahan dan sakit hati membuat sang raja menjadi sosok yang kejam dan dingin. Untuk melampiaskan kemarahannya, ia menikahi gadis-gadis dan membunuhnya keesokan harinya.

Kesepian yang dirasakannya setiap malam membuatnya takut dan teringat akan istrinya, sehingga akhirnya ia memanggil penasehat kerajaan dan memerintahkan sang penasehat untuk membawakan seorang gadis cantik untuk dinikahinya sekaligus mengundang tukang jagal ke pernikahan tersebut. Raja berkara: "Aku akan menikahi gadis itu pagi ini dan keesokan harinya aku akan memenggal lehernya sebelum ia berhenti mencintaiku. "Sang penguasa Sasan menikah setiap hari, hal ini berlangsung selama tiga tahun, seribu pengantin wanita, seribu eksekusi dan seribu wanita hilang. (SSM: 1-2)

Dominasi Id pada diri sang raja juga membuatnya menjadi keras hati sehingga raja tidak mau mendengar nasehat untuk menghentikan tindakan buruknya yang terus membunuh gadisgadis di negerinya.

Tindakan sang raja membunuh istriistri yang dinikahinya dalam satu hari merupakan bentuk pembalasan dendamnya kepada istri pertamanya yang telah mengkhianatinya. Rasa marah membuat sang raja mengambil tindakan yang sangat kejam. Tindakan kejam ini didorong oleh Id yang memang pada dasarnya mendorong manusia untuk memuaskan kebutuhannya. Dengan membalaskan dendamnya, sang raja merasakan kepuasan karena kebutuhannya untuk melampiaskan kemarahannya terpenuhi. Dalam hal ini dorongan $I d$ tidak selalu realisitis. Id sang raja memerintahkannya untuk mendapatkan kesenangan dengan 
Jurnal Ilmu Budaya, Vol. 17, No. 1 Agustus Tahun 2020

membalaskan dendam dan kemarahannya pada wanita-wanita yang dinikahinya, maka rajapun mengikuti perintah $I d$ yang dalam hal ini tindakan pemuasan dan pemenuhan keinginan raja untuk mendapat kesenangan dan kepuasan menimbulkan keresahan masyarakat. Id merupakan komponen kepribadian yang hanya bekerja untuk memuaskan hasrat manusia karena itulah Id itu tidak realistis dan tidak memiliki nilai moralitas sehingga tidak dapat membedakan hal yang baik atau buruk. Jadi, bila sang raja hanya dikuasai oleh $I d$, maka tindakannyapun tidak realisitis dan tidak mempertimbangkan sisi moralitas. Namun karena Id memiliki energi pendorong yang sangat besar, maka dapat dipahami mengapa raja bertindak menuruti dorongan Id nya. Hal ini dimungkinkan karena Id tidak terpengaruh pada realitas, logika ataupun dunia kehidupan sehari-hari disebabkan Id beroperasi pada level tidak sadar. Jadi, Id selalu mendorong manusia untuk segera mendapatkan kepuasan (pleasure principle) tanpa mempertimbangkan akibat yang ditimbulkan dari tindakan yang mengikuti dorongan tersebut.

Selain menuruti dorongan Id dengan melampiaskan kemarahan dan dendamnya melalui hukuman mati yang diterapkannya kepada setiap wanita yang dinikahinya, sang raja juga menuruti dorongan Idnya dengan menikahi wanita-wanita tersebut. Menikahi dan menghukum wanita-wanita tersebut, keduanya merupakan prilaku yang didorong oleh tuntutan $I d$.

\section{B. Ego}

Ketika sang raja mendengar permintaan adik Shahrazad (Dunyazad) agar Shahrazad bercerita untuk terakhir kalinya, raja menjadi tertarik. Ketertarikan raja untuk mendengar cerita Shahrazad didorong oleh keingintahuannya. Tindakan ini merupakan bentuk Ego yang menyikapi realitas yang ada. Pada malam pertama pernikahannya, tanpa sengaja raja mendengar Dunyazad meminta Shahrazad bercerita dan raja tertarik untuk ikut mendengarkannya, namun 
Jurnal Ilmu Budaya, Vol. 17, No. 1 Agustus Tahun 2020

karena ada urusan negara yang harus

dibicarakannya ia menunda pembunuhan terhadap Shahrazad dan memintanya menceritakan cerita tersebut hari berikutnya.

Dunyazad berkata kepada shahrazad: "Oh, kakakku tercinta, betapa kami semua akan merindukan engkau nanti, tak ada lagi suara nyanyianmu, permainan sulingmu, dan terutama tidak ada lagi cerita-cerita indah yang dapat kami dengar setiap malam darimu, cerita-cerita yang dapat mengusir kekosongan dan kesepian kami di malam hari. Tak ada seorangpun di negeri Arab ini yang dapat bercerita seindah dirimu. Maukah kau bercerita padaku untuk yang terakhir kalinya? (SSM: 2)

Permintaan Dunyazad agar kakaknya bercerita mengingatkan sang raja akan masa kecilnya dimana ia selalu diceritakan cerita pengantar tidur oleh ibunya. Hal ini makin memperkuat ketertarikannya untuk mendengarkan cerita Shahrazad. Karena itulah ketika ia sudah menyelesaikan urusannya ia bertanya kepada Shahrazad, "Shahrazad, cerita apa yang engkau ceritakan kepada adikmu malam ini?" Shahrazad menjawab bahwa dia menceritakan kisah petualangan "Sinbad si Pelaut," petualangan di tengah lautan, melewati gunung, air, dimana banyak binatang buas dan pulau-pulau yang menakjubkan. Ketertarikan raja akan cerita Shahrazad membuatnya menunda pembunuhan terhadap Shahrazad dan meminta algojo datang kembali esok hari.

Keputusan raja menunda hukumannya kepada Shahrazad disebabkan oleh rasa ingin tahunya dengan cerita Shahrazad merupakan tindakan yang didorong oleh Ego. Sebagai komponen pikiran yang dapat berhubungan dengan dunia luas Ego memiliki peran sebagai pembuat keputusan yang menjembatani dorongan Id dan Superego dengan menyesuaikan dengan tuntutan yang datang dari dunia luar. Ego merupakan satu-satunya komponen kepribadian yang berada pada wilayah sadar, bawah sadar dan tidak sadar, sehingga Ego memiliki peran untuk mengambil keputusan pada tiga level alam pikiran tersebut. Sebagai komponen yang menjembatani Id dan Superego, 
Jurnal Ilmu Budaya, Vol. 17, No. 1 Agustus Tahun 2020

keputusan raja untuk menunda hukuman kepada Shahrazad merupakan tindakan Ego dalam mengendalikan Id. Dalam hal ini Ego berjuang meredam dorongan Id dengan memutuskan penundaan hukuman terhadap Shahrazad sebagai bentuk tindakan yang disesuaikan dengan keadaan realitas yang terjadi. Jadi, dalam hal ini, Ego berhasil menundukkan Id sebagaimana seorang penunggang kuda berhasil menundukkan kudanya. Walaupun tidak selalu Ego dapat berhasil menundukkan dorongan Id yang besar. Dalam kondisi tertentu disaat Ego tidak dapat menundukkan $I d$, maka pikiran manusia menciptakan mekanisme pertahanan diri.

Ego yang menuntun seseorang untuk bertindak rasional dan realistis membuat sang raja memutuskan untuk mendengarkan cerita Shahrazad dan secara logis menuntunnya untuk menunda hukuman terhadap istrinya itu. Tindakan sang raja memperlihatkan kekuasaannya sebagai pemilik kekuasaan. Dengan posisinya sebagai penguasa, raja sangat menyadari bahwa dengan tahta yang dimilikinya dia dapat berbuat sesuai dengan keinginannya. Dengan tindakannya yang membunuh wanitawanita yang dinikahinya, raja dapat melakukannya tanpa mendapat hukuman atau sanksi apapun dari tindakan buruknya itu. Jadi, realitas yang ada di depan matanya, yang secara logis menempatkan sang raja sebagai penguasa tunggal yang dapat berbuat sesuai dengan keinginannya, membuat raja memanfaatkan kekuasaannya tersebut untuk melampiaskan dendamnya dengan cara yang tidak arif. Dengan menyadari tidak ada yang dapat menghentikannya atau menghalanginya dari tindakannya tersebut, membuat sang raja memanfaatkan dorongan Egonya untuk berbuat sesuai dengan realiatas yang ada.

\section{Superego}

Maka pada malam hari Shahrazad bercerita sehingga tidak terasa waktu sudah berubah menjadi pagi. Shahrazad adalah seorang wanita yang pintar, ia sengaja menghentinya ceritanya disaat cerita tersebut belum selesai sehingga 
Jurnal Ilmu Budaya, Vol. 17, No. 1 Agustus Tahun 2020

membuat raja penasaran akan akhir kisah

itu. Jadi, karena raja ingin sekali mendengar kelanjutan cerita tersebut, maka pagi itu ia menangguhkan kembali hukuman mati untuk istrinya dan menyuruh algojo untuk kembali lagi esok hari.

Hal itu berlangsung setiap malam sehingga pada malam ke seribu setelah Shahrazad menikahi raja, Shahrazad sudah kehabisan cerita, tidak ada lagi cerita yang bisa ia ceritakan kepada raja, maka di malam ke seribu satu, ia menceritakan kisah hidupnya sendiri. Mendengar kisahnya itu, rajapun tersadar dan kesadaran itu membuat raja terbuka hatinya dan ia mulai mencintai Shahrazad.

Shahrazad berhasil mengembalikan kepercayaan raja terhadap perempuan sehingga pada akhirnya ia dapat mencintai Shahrazad. Apa yang dialami sang raja didorong oleh Superego dimana Superego membawanya untuk melihat sisi baik pada diri Shahrazad sehingga dapat mengembalikan kepercayaannya terhadap wanita dan tidak menyamakan
Shahrazad dengan istri pertamanya yang tidak setia. Perubahan raja ini mengembalikannya pada dirinya yang sebenarnya sebagai laki-laki yang baik, raja yang baik, yang dicintai rakyatnya. Ini terjadi dengan adanya peran Superego yang membawanya kembali kepada hati nuraninya, "Raja tersadar mendengar cerita tersebut dan akhirnya hati raja terbuka dan sejak itu ia mencintai Shahrazad." (SSM: 3)

Perubahan yang terjadi pada diri sang raja yang kembali kepada hati nuraninya memperlihatkan bagimana Superego berperan dalam perubahan itu. Hal ini dimungkinkan karena pada dasarnya sang raja adalah seorang lakilaki yang baik sehingga ketika Id menguasainya, ia berubah menjadi sosok yang dingin dan kejam, namun karena pada dasarnya ia seorang yang baik, maka Superego mengembalikannya pada nuraninya. Nuraninya yang baik sangat berperan dalam memberi kesempatan pada Superego untuk kembali pada pribadinya yang sebenarnya. Karena itulah dalam tindakannya, tanpa ia sadari, 
Jurnal Ilmu Budaya, Vol. 17, No. 1 Agustus Tahun 2020

ia didorong oleh Superegonya seperti tindakannya yang memberi peluang pada Shahrazad untuk bercerita. Walaupun ia didorong secara sentimental oleh kenangan masa kecilnya ketika diceritakan oleh ibunya, namun kebaikan hatinya membuatnya memberi kesempatan pada Shahrazad untuk bercerita dan dengan penuh perhatian ia mendengarkan cerita-cerita Shahrazad sampai menghabiskan waktu 1001 malam. Ini memperlihatkan bahwa pada dasarnya raja adalah seorang yang menghargai wanita karena itulah ia mau mendengarkan walaupun cerita dari seorang perempuan.

Hal lain yang dapat menggugah dan meningkatkan dorongan Superego pada diri sang raja adalah tokoh-tokoh dalam cerita-cerita yang dituturkan oleh Shahrazad. Sebagian besar tokoh yang menjadi sosok penting dalam kisah-kisah tersebut seperti Sinbad, Ali Baba dan tokoh-tokoh utama lainnya bertutur tentang sosok yang mengedepankan moralitas dalam hidupnya. Hal ini mendorong Superego sang raja menjadi dominan. Maka kondisi-kondisi seperti ini memicu perubahan yang dialami sang raja untuk kembali menjadi sosok yang baik dan arif.

Sebagai upaya menghargai ceritacerita Shahrazad yang sangat menarik, lalu raja meminta penasehatnya untuk mengundang 100 ahli tulis yang bisa menulis dengan indah. Para ahli tulis itu diminta untuk menuliskan semua kisah yang telah diceritakan Shahrazad selama seribu satu malam pernikahannya dengan Shahrazad (SSM : 3).

\section{Simpulan}

Kisah Seribu Satu Malam, memperlihatkan bahwa dalam kehidupannya, tokoh utama kisah ini yaitu sang raja, didorong oleh ketiga komponen struktur kepribadian Freud; Id, Ego dan Superego.

Prilaku raja Shahryar yang sangat jelas memperlihatkan dominasi $I d$ adalah ketika raja memerintahkan penasehatnya untuk mencarikan seorang wanita yang akan dinikahinya lalu dihukum mati keesokan harinya. Tindakan ini dipicu 
Jurnal Ilmu Budaya, Vol. 17, No. 1 Agustus Tahun 2020

oleh dorongan $I d$ yang sangat kuat untuk

mendapatkan kesenangan dan kepuasan dengan melampiaskan dendam dan kemarahannya akibat pengkhiatan istri pertamanya. Jadi, tindakannya menikahi dan membunuh wanita-wanita tersebut merupakan prilaku yang didominasi oleh Id.

Selanjutnya, ketertarikan raja Shahryar untuk mendengarkan cerita Shahrazad merupakan respon dalam menyikapi realitas, yang merupakan dorongan Ego. Selain itu, dominasi Ego juga terlihat ketika raja Shahryar mengedepankan kekuasaannya karena ia sangat menyadari bahwa dengan tahtanya ia menjadi penguasa yang dapat melakukan apapun yang ia inginkan tanpa ada sanksi apapun, walalupun tindakan itu tidak baik.

Dorongan Superego pada raja Shahryar terlihat pada saat Superego membawanya kembali pada hati nuraninya sehingga ia dapat menerima Shahrazad setelah seribu malam pernikahan mereka. Dengan hal ini, Superegonya berhasil mengalahkan
Idnya. Selain itu dorongan Superego juga tercermin dari prilaku raja Shahryar yang memberi peluang kepada Shahrazad untuk bercerita dan rajapun dengan antusias mendengarkan cerita-cerita tersebut. Lebih jauh lagi, tokoh-tokoh dalam cerita-cerita yang dikisahkan oleh Shahrazad juga memicu dorongan Superego pada diri sang raja.

\section{Daftar Pustaka}

Barry, Peter. 1995. Beginning Theory: An Introduction to Literary and Cultural Theory. Manchester: Manchester University Press.

BEM Psikologi UnDip. 2015. Seputar Teori Freud: Id, Eg dan Superego dalam KABINET, Nuansa Baru, terbit 28 Pebruari 2015, Semarang: UnDip.

Hima, Ghusyara. 2015. Id, Ego, Superego: Psikoanalisis Kepribadian Sigmund Freud, dalam https://www.kompasiana.com/ghus yarahimapramudhitan/552fa1546ea 834a8048b4586/Id-Ego-Superegopsikoanalisis-kepribadian-sigmundfreud, diakses pada 12 Juni 2020, jam 15.00.

Lechte, John. 1995. Fifty Key Contemporary Thinkers From 
Jurnal Ilmu Budaya, Vol. 17, No. 1 Agustus Tahun 2020

Structuralism to Postmodernity.

London: Routlegde.

Milner, Max. 1992. Freud dan Interpretasi Sastra, terj. Apsanti. $D S$. Jakarta: Intermasa.

Sim, Stuart (ed.). 1995. A-Z GuIde to Modern Literary and Cultural Theorists. London: Prentice Hall/Harvester Wheatsheaf. 